\title{
Thermoelectric Generators Based on Ionic Liquids
}

\author{
EDITH LAUX (i) ${ }^{1,3}$ STEFANIE UHL, ${ }^{1}$ LAURE JEANDUPEUX, ${ }^{1}$ \\ PILAR PÉREZ LÓPEZ, ${ }^{2}$ PAULINE SANGLARD,${ }^{2}$ ENNIO VANOLI, ${ }^{2}$ \\ ROGER MARTI, ${ }^{2}$ and HERBERT KEPPNER ${ }^{1}$
}

1.-Haute Ecole Arc Ingénierie (HES-SO), Eplatures-Grise 17, 2300 La Chaux-de-Fonds, Switzerland. 2.-Haute école d'ingénierie et d'architecture (HES-SO), Perolles 80, 1705 Fribourg, Switzerland. 3.-e-mail: edith.laux@he-arc.ch

Looking at energy harvesting using body or waste heat for portable electronic or on-board devices, Ionic liquids are interesting candidates as thermoactive materials in thermoelectric generators (TEGs) because of their outstanding properties. Two different kinds of ionic liquid, with alkylammonium and choline as cations, were studied, whereby different anions and redox couples were combined. This study focussed on the intention to find non-hazardous and environmentally friendly ionic liquids for TEGs to be selected among the thousands that can potentially be used. Seebeck coefficients (SEs) as high as - $15 \mathrm{mV} / \mathrm{K}$ were measured, in a particular case for an electrode temperature difference of $20 \mathrm{~K}$. The bottleneck of our TEG device is still the abundance of negative SE liquids matching the internal resistance with the existing positive SE-liquids at series connections. In this paper, we show further progress in finding increased negative SE liquids. For current extraction from the TEG, the ionic liquid must be blended with a redox couple, allowing carrier exchange in a cyclic process under a voltage which is incuced by the asymmetry of the generator in terms of hot and cold electrodes. In our study, two types of redox pairs were tested. It was observed that a high SE of an ionic liquid/redox blend is not a sufficient condition for high power output. It appears that more complex effects between the ionic liquid and the electrode determine the magnitude of the final current/power output. The physico-chemical understanding of such a TEG cell is not yet available.

Key words: Ionic liquid, thermoelectric generator, environmentally friendly, energy harvesting, body/waste heat, Seebeck coefficient

\section{INTRODUCTION}

As ionic liquids permit a light-weight and flexible thermoelectrical generator (TEG) design without any harmful components, they can significantly contribute to power-supply autonomous systems for wearable applications. For body-heat-based energy harvesting, a good and pleasant contact with the skin is crucial. Solid-state TEGs, for example based on BiTe, therefore use thin-film technologies to fabricate flexible modules. $^{2}$ However, a major disadvantage is the strong decline of the temperature difference between

(Received August 14, 2017; accepted February 23, 2018; published online March 7, 2018) the warm and cold surfaces due to the too high thermal conductivity, and, thus, the output voltage. As ionic liquids have a lower thermal conductivity and therefore higher Seebeck-coefficients (SEs) ${ }^{3}$ they might be more suitable despite a still lower power output compared to solid-state BiTe-TEGs.

Why is the voltage output that important? Autonomous systems consist in general of an energy management and storage unit to condition the voltage level and to provide the necessary power even if no energy can be harvested. The power management unit* needs a minimum input voltage

*EM Marin, Texas Instruments, Linear Technology, Analog Devices. 
for its operation which is, for some wearable applications, an issue due to the low temperature difference between the skin and the ambient air. As an example, the integrated circuit EM8500 from EM Marin needs, under cold-start conditions, a voltage of $0.3 \mathrm{~V}$ and a power of $3 \mu \mathrm{W} .^{4}$

Ionic liquids show high $\mathrm{SEs}^{3}$ (Figs. 1 and 2); however, the power output of currently screened ionic liquids are still quite low compared to conventional materials such as BiTe.

To fulfil the compromise of finding materials having simultaneously a high Seebeck coefficient, a low thermal conductivity $\left(\sigma_{\mathrm{th}}\right)$ and high electrical conductivity $\left(\sigma_{\mathrm{el}}\right)$ limits the choice, looking at solidstate TEG solutions. The figure-of-merit in Eq. 1 is well known as the key criterion for obtaining high thermal conversion efficiencies for solid-state-based TEGs:

$$
Z \cdot T=S E^{2}\left(s_{\mathrm{el}}\right) \cdot T /\left(s_{\mathrm{th}}\right)
$$

Due to the lack of solid-state alloys, TEGs have been constructed of combinations of elements such as Bi, $\mathrm{Te}, \mathrm{Pb}, \mathrm{Sb}, \mathrm{Ag}, \mathrm{Yb}$, and $\mathrm{Co}$, creating morphological modifications such as multilayer and/nano-wire structures. A review is given in Ref. 5.

Looking at ionic liquids for TEGs, in contrast a rather overwhelming platform of promising liquids is potentially at hand; an overview of physical and chemical properties is given in Ref. 6 . The work in Ref. 7, using simulation approaches, looks at predicting the values and the signs of SE for a given ionic liquid in the function of the chemical construction of the ion and redox couples. The simulation was based on existing experimental data. There is doubtless much more work needed to extend the database in order to get the full theoretical insight. At present, the understanding of how ion properties together with macroscopic properties, such as conductivity and viscosity, make up the Seebeck coefficient is not yet available. This paper aims to contribute to the data of new ionic liquids that are non-toxic and therefore interesting in the field of biomedical applications.

The way that these liquids are brought to applications will need a series connection, whereby voltages of more than $300 \mathrm{mV}$ are required for running MEMS-based microsystems. In general, more than 100 individual generator cells must be placed between the heat source and the heat drain. To increase the total TEG potential, positive Seebeck coefficient cells must be put in series with negative ones having the same internal resistance for a given temperature difference.

Looking at the power consumption of batteryoperated systems (e.g., wireless sensors, wristwatchs $)^{8}$ and the developments towards a 'ZeroPower Technological Platform for Autonomous Smart Systems, ${ }^{9}$ the targets (Table I) seem within reach.

It has been shown in a previous publication ${ }^{10}$ that the limiting effect of the overall TEG power output

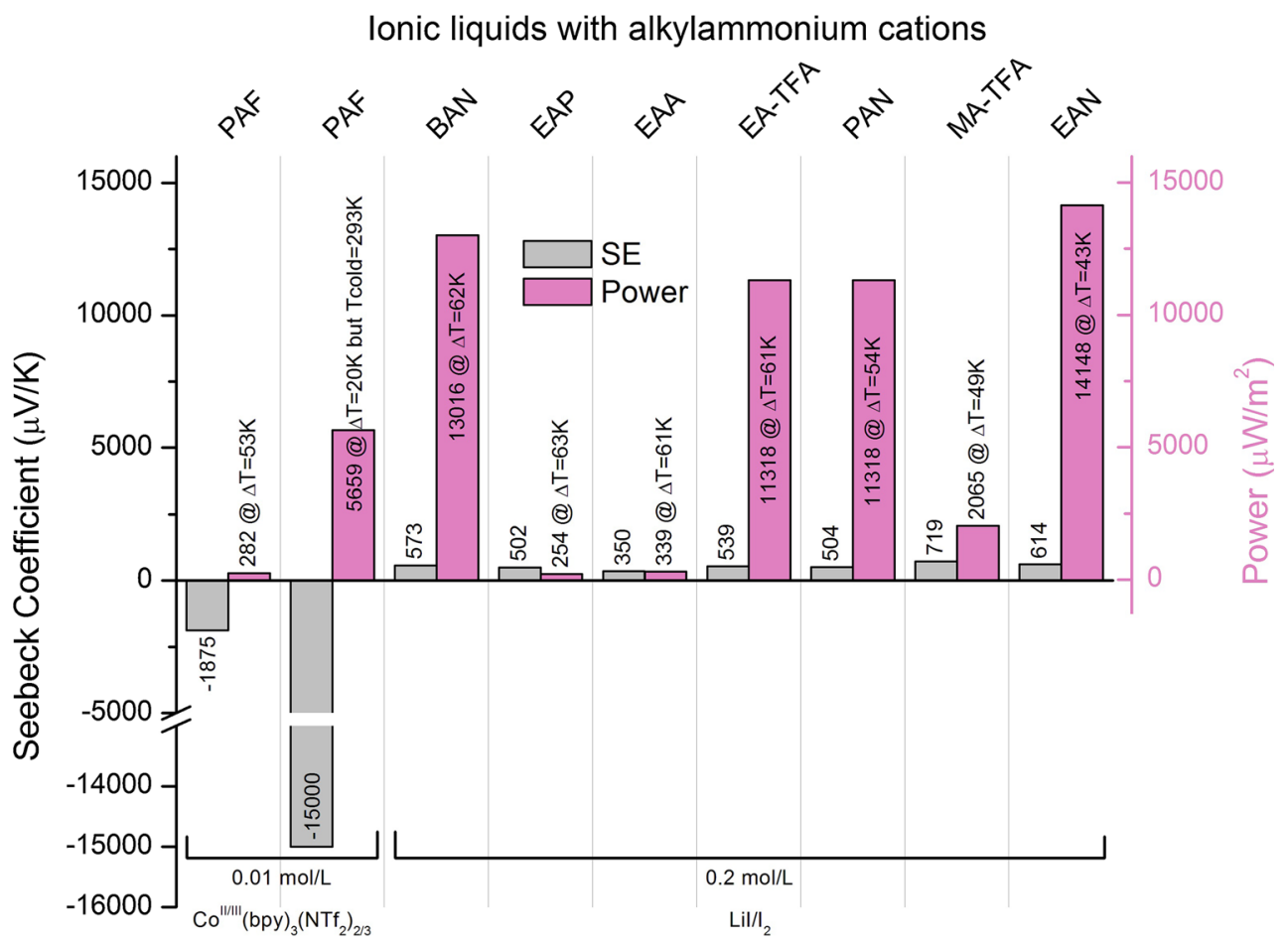

Fig. 1. Measured values for SE and power output for a series of alkylammonium cations and various anions at different temperature gradients with Tcold kept at $295 \mathrm{~K}$. The values $S E(\mu \mathrm{V} / \mathrm{K})$ and Power $\left(\mu \mathrm{W} / \mathrm{m}^{2}\right)$ are indicated for each ionic liquid. The temperature-gradient is indicated as @ $\Delta T(\mathrm{~K})$. 


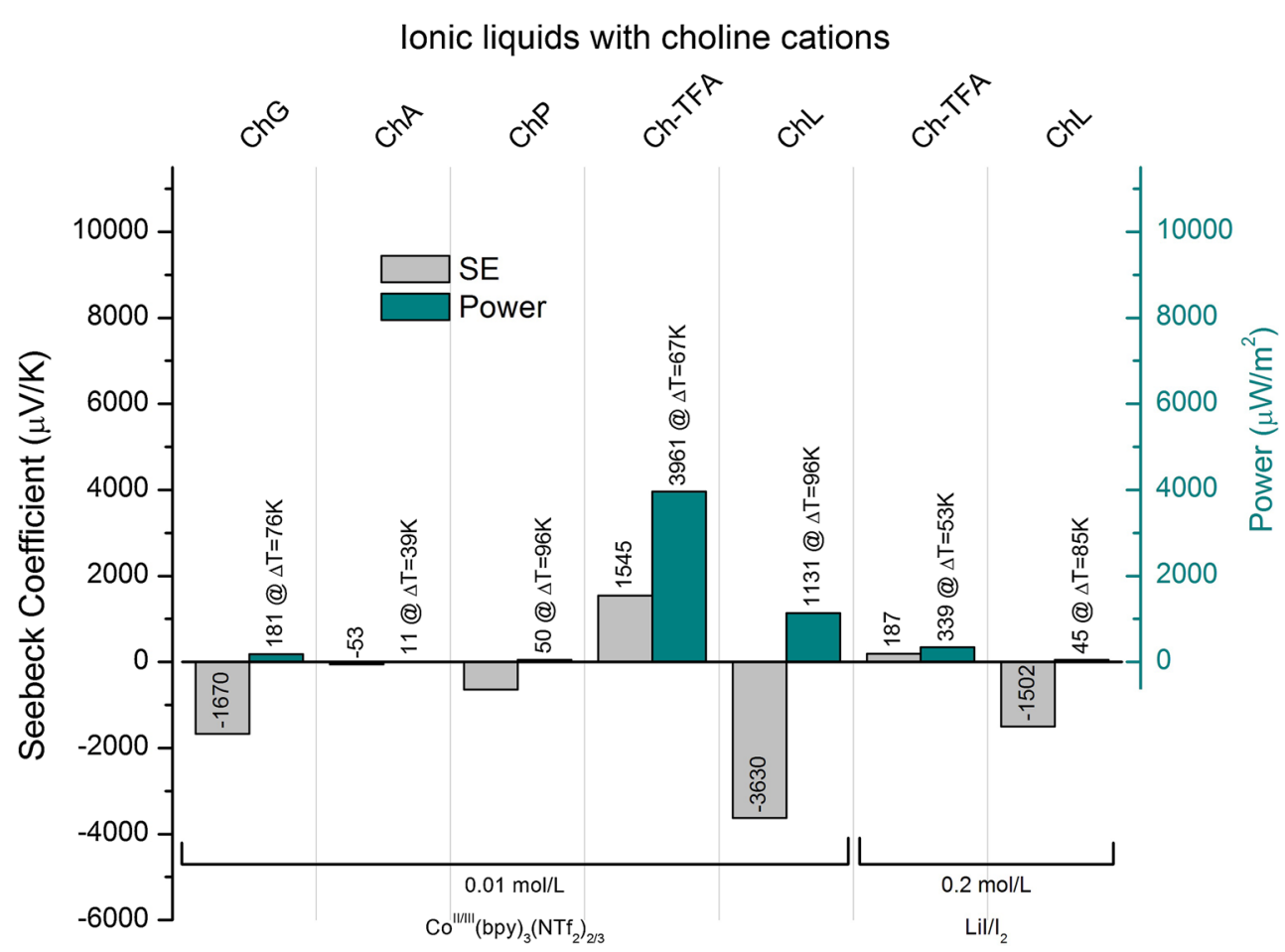

Fig. 2. Measured values for SE and power output for a series of choline as cations and various anions at different temperature gradients with Tcold kept at $295 \mathrm{~K}$. The values $S E(\mu \mathrm{V} / \mathrm{K})$ and Power $\left(\mu \mathrm{W} / \mathrm{m}^{2}\right)$ are indicated for each ionic liquid. The temperature gradient is indicated as @ $\Delta T$ $(\mathrm{K})$.

Table I. Energy demand of current autonomous systems and the targets set by the European project 'Guardian Angels for a Smarter Life: Enabling a Zero-Power Technological Platform for Autonomous Smart Systems, ${ }^{\text {9 }}$

\begin{tabular}{lccc}
\hline & Current status & & Target \\
\cline { 2 - 2 } Sensing & $10-100 \mu \mathrm{W}$ & & $100 \mathrm{nW}$ \\
Computation & $100 \mathrm{aJ} / \mathrm{op}$ & & $0.1 \mathrm{aJ} / \mathrm{op}$ \\
Communication & $1-10 \mathrm{~nJ} / \mathrm{bit}$ & & $1 \mathrm{pJ} / \mathrm{bit}$ \\
\hline
\end{tabular}

is internal cell resistance $R_{\mathrm{i}}$ of the $n$-type ionic liquid that must be matched with the $R_{\mathrm{i}}$ of the $p$ type rather than its SE. All the charge carriers that leave the TEG to an external consumer are entirely due to oxidation/reduction mechanisms of the redoxactive species which is assumed to occur in the double layers at the hot and cold liquid-to-electrode interface. Hence, the origin of the voltage across the TEG in a $\Delta T$-application is entirely based on the thermally induced asymmetry of the ionic liquids/ redox couple in the proximity of the electrodes. This paper chooses such kinds of ionic liquids that are particularly non-toxic; even amino acid-like substances have been used. Hence, the motivation of the screening was this aspect. At the beginning of such a screening study, the first parameter to be analyzed was the Seebeck coefficient which is linked to the open circuit voltage. The current extraction was, in a second step, optimized by the choice, its concentration, and the chemical "compatibility" as a blend in the ionic liquid and with the choice of electrode material. In our study, to reduce electrode issues, a very stable metal, such as rhodium, was chosen.

\section{EXPERIMENTAL}

A wide range of SEs and power outputs were measured for ionic liquids with two different redox couples, $\left(\mathrm{I}_{2} / \mathrm{LiI}\right.$ and $\left.\mathrm{CoII} / \mathrm{III}(\mathrm{bpy})_{3}\left(\mathrm{NTf}_{2}\right)_{2 / 3}\right)$. The choice of redox couples was based on the possibility of dissolving them in the choice of ionic liquids; this is not straightforward due to the absence of solvents, but also due to the need of low redox potentials. The temperature difference across the junctions varied, while T(cold) was kept constant at $298 \mathrm{~K}$. The current-voltage characteristics of 14 different Ionic liquid-based TEGs have been performed in a specially designed test cell described in a previous publication ${ }^{11}$ : In all the experiments, rhodium-coated sapphire electrodes were used. The active electrode area $\left(4.3 \mathrm{~cm}^{2}\right)$ in contact with the liquid has a larger diameter as compared to the distance between the electrodes $(0.5 \mathrm{~cm})$. All the described effects and conclusions may be limited by the choice of these electrodes. The test cell allowed for applying a defined temperature difference between the electrodes in order to measure the 
Table II. Chemical structure of cations and anions of the ILs used

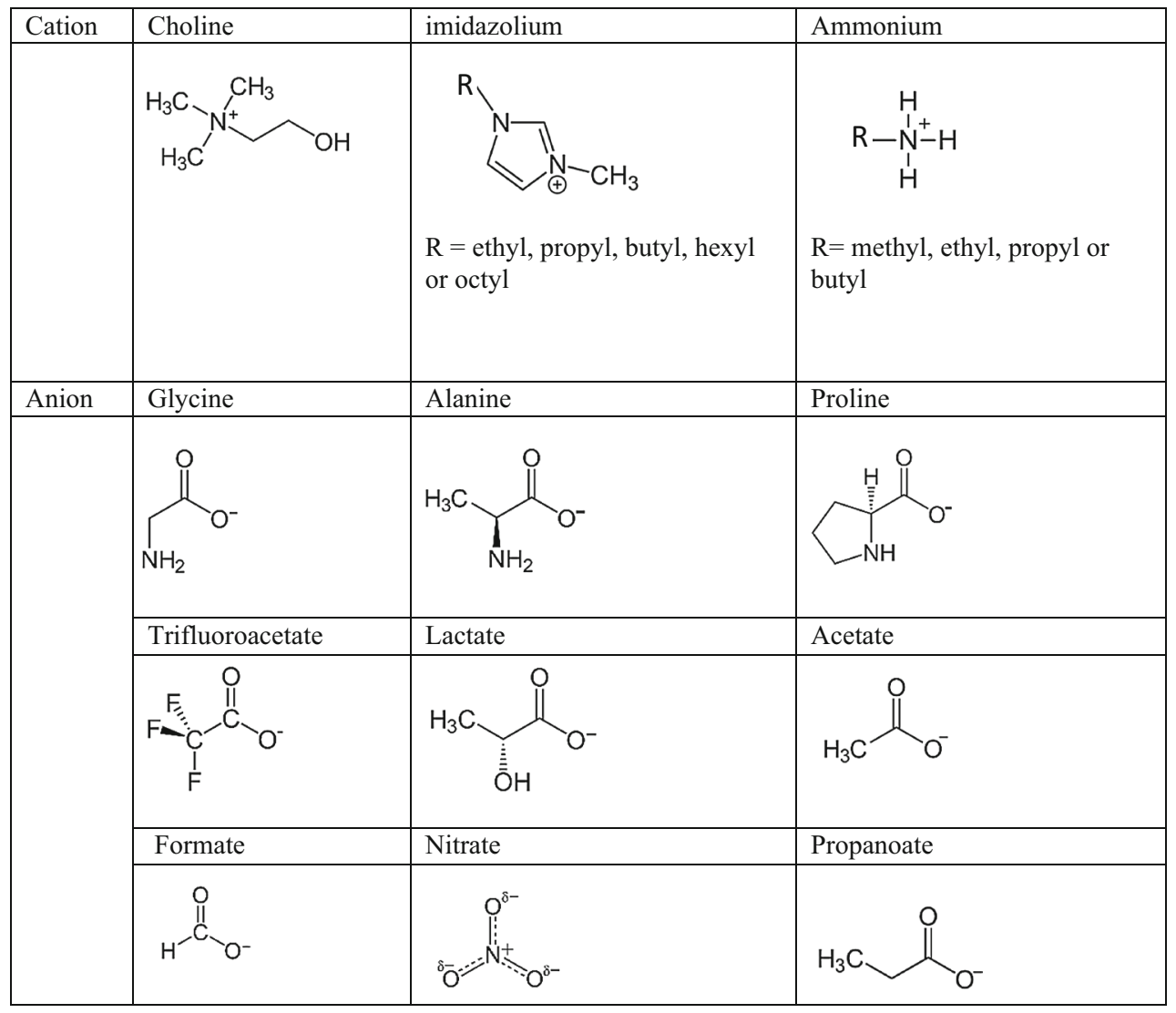

potential difference between the electrodes (SE), and to obtain the $\mathrm{I}-\mathrm{V}$ characteristics and the power output. The latter is achieved by varying the external load of the TEG.

For current extraction, a redox couple of $0.2 \mathrm{~mol} / \mathrm{L}$ of $\mathrm{I}_{2} / \mathrm{LiI}$ or $0.01 \mathrm{~mol} / \mathrm{L}$ of $\mathrm{CoII} / \mathrm{III}(\mathrm{bpy})_{3}\left(\mathrm{NTf}_{2}\right)_{2 / 3}$ was added to the ionic liquids. This work must be considered as a kind of screening for setting up a list of such ionic liquids that are or are not promising for TEGs. The authors assume that testing a ionic liquid without, with a weak and with an increased redox concentration is sufficient for such a list.

\section{MATERIALS AND METHODS}

Seebeck coefficients and power outputs were measured for 14 systems of ionic liquids and redox couples with appropriate concentrations: propylammonium formate (PAF), butylammonium nitrate (BAN), ethylammonium propanoate (EAP), ethylammonium acetate (EAA), ethylammonium trifluoroacetate (EATFA), propylammonium nitrate
(PAN), methylammonium trifluoroacetate (MATFA), ethylammonium nitrate (EAN), choline glycine (ChG), choline alanine (ChA), choline proline (ChP), choline trifluoroacetate (ChTFA), choline lactate (ChL), and choline trifluoroacetate (ChTFA). All ionic liquids and $\mathrm{CoII} / \mathrm{III}(\mathrm{bpy})_{3}(\mathrm{NTf} 2)_{2 / 3}$ were synthetized and provided by HES-SO Fribourg. LiI and $\mathrm{I}_{2}$ was purchased from Sigma-Aldrich.

The structure of the three types of cations and the corresponding anions of the ionic liquids used in this study are represented in Table II.

The SE values are the open ciruit voltages of the TEGs for a given $\Delta T$. By loading the generator using high precision resistors, the output current can be determined for the Seebeck coefficient and the open circuit voltage by using a high impedance voltmeter.

\section{RESULTS AND DISCUSSION}

The data obtained for the Seebeck coefficients and power outputs are summarized in Figs. 1 and 2. Alkylammonium-based ionic liquids showed rather 
positive SEs whereas choline-based ionic liquids exhibited both positive and negative SEs for both types of redox couple. The highest negative SE of about $-15 \mathrm{mV} / \mathrm{K}$ was observed for $\mathrm{PAF}$, a protic ionic liquid with $0.2 \mathrm{~mol} / \mathrm{L} \mathrm{LiI} / \mathrm{I}_{2}$ as a redox ouple with a reduced temperature difference of $20 \mathrm{~K}$ (Tcold $293 \mathrm{~K}$ and Thot $313 \mathrm{~K}$ ). The highest positive $\mathrm{SE}$ value of $1.545 \mathrm{mV} / \mathrm{K}$ was measured for CChTFA with $\left.0.01 \mathrm{~mol} / \mathrm{L} \mathrm{CoII/III(bpy})_{3}\left(\mathrm{NTf}_{2}\right)_{2 / 3}\right)$ as a redox couple.

Highest power output was measured for EAN with $14.15 \mathrm{~mW} / \mathrm{m}^{2} @ \Delta T 43 \mathrm{~K}$ with a positive SE of $0.614 \mathrm{mV} / \mathrm{K}$ and $\mathrm{ChL}$ with $1.13 \mathrm{~mW} / \mathrm{m}^{2} @ \Delta T 96 \mathrm{~K}$ with negative SE.

Looking at Fig. 1, three observations are straightforward:

1. High SE low power.

2. Moderate SE moderate power.

3. Moderate SE and high power.

Taking $\mathrm{LiI} / \mathrm{I}_{2}$ as a redox couple, all ionic liquids show moderate SE and moderate and very high power. For all the measured nitrides as anions, high power outputs $\left(>10 \mathrm{~mW} / \mathrm{m}^{2}\right)$ are achieved, while the others of this class show reduced power values.

Using PAF with CoII/III (bpy $\left.)_{3}\left(\mathrm{NTf}_{2}\right)_{2 / 3}\right)$ as a redox couple, both moderate and very high SEs and moderate and high power are observed, depending on the temperature difference. The SE depends on the temperature difference and the regime where the measurement is carried out (Tcold $=298 \mathrm{~K}$ and Thot $=351 \mathrm{~K}$, or Tcold $=293 \mathrm{~K}$ and Thot $=333 \mathrm{~K}$, respectively).

Figure 2 illustrates that, for the choline based ionic liquids, negative and positive SEs with low and moderate values can be prepared showing low and moderate power outputs, independent of the choice of the redox couples.

The physico-chemical explanation (structure, polarization, charge location, anion/cation size, redox couple) for the appearance of positive and negative SEs is not straightforward and should be studied in more detail.

\section{SUMMARY AND CONCLUSION}

For two series of alkylammonium- and cholinebased ionic liquids, the values for SE and power output differ strongly, meaning there is no direct correlation between SE and power. The link between the Seebeck coefficient and power is current extraction, which can be identified as a key factor for TEG efficiency. In this paper, we have identified ionic liquids with increased values for $\mathrm{SE}$ and power for the $p$ - / $n$-type. Careful tailoring of the temperature range, redox type and concentration will lead to improved TEG power. Further investigation is needed for a better understanding of the relationship between ionic liquids and redox couples for current extraction.

\section{ACKNOWLEDGEMENTS}

The authors acknowledge the financial support of the Haute Ecole Spécialisée de Suisse occidentale, HES-SO Interdisciplinary Project No. 011-2015-PI and the European Union's Horizon 2020 research and innovation programme under Grant Agreement No. 731976". H2020-FETPROACT Grant No. 731976 Magenta.

\section{OPEN ACCESS}

This article is distributed under the terms of the Creative Commons Attribution 4.0 International License (http://creativecommons.org/licenses/by/4.0/), which permits unrestricted use, distribution, and reproduction in any medium, provided you give appropriate credit to the original author(s) and the source, provide a link to the Creative Commons license, and indicate if changes were made.

\section{REFERENCES}

1. V. Leonov and R.J.M. Vullers, J. Electron. Mater. (2009). https://doi.org/10.1007/s11664-008-0638-6.

2. E. Schwyter, W. Glutz, L. Durrer, and Ch Hierold, DTIP (2008). https://doi.org/10.1109/DTIP.2008.4752949.

3. E. Laux, S. Uhl, T. Journot, J. Brossard, L. Jeandupeux, and H. Keppner, J. Electron. Mater. 45, 3383 (2016).

4. EM Microelectronic-Marin SA, Datasheet EM8500, www. emmicroelectronic.com. Accessed 27 July 2017.

5. T.M. Tritt and M.A. Subramanian, MRS Bull. 31, 188 (2006).

6. S. Zhang, N. Sun, X. He, X. Lu, and X. Zhang, J. Phys. Chem. Ref. Data 35, 1475 (2006).

7. A. Sosnowska, M. Barycki, A. Gajewicz, M. Bobrowski, S. Freza, P. Skurski, S. Uhl, E. Laux, T. Journot, L. Jeandupeux, H. Keppner, and T. Puzyn, ChemPhysChem (2016). https://doi.org/10.1002/cphc.201600080.

8. R.J.M. Vullers, R. van Schaijk, I. Doms, C. Van Hoof, and R. Mertens, Solid-State Electron. 53, 684 (2009).

9. A.M. Ionescu and C. Hierold, Procedia Comput. Sci. 7, 43(2011).

10. H. Keppner, S. Uhl, E. Laux, L. Jeandupeux, J. Tschanz, and T. Journot, Mater. Today: Proc. 2, 680 (2015).

11. S. Uhl, E. Laux, T. Journot, L. Piervittori, L. Jeandupeux, and H. Keppner, JECM 3, 42 (2016). 